\title{
NOTAS
}

\section{ANTIGUO ESPAÑOL Y GALLEGOPORTUGUÉS TROCIR 'PASAR'}

Este verbo es altamente característico de los textos más antiguos redactados en castellano, riojano y leonés; después de 1300 apenas aflora a la superficie (los copistas lo estropean), si bien continúa vegetando en los dialectos conservadores y alguna rara vez penetra en el léxico de un escritor apegado a la tradición local ${ }^{1}$. Se trata, pues, de una de esas voces patrimoniales rechazadas por las generaciones de literatos que vivían en el ambiente de Alfonso el Sabio y de don Juan Manuel, quienes tamizaron el caudal léxico con marcado esmero.

He aquí los vestigios que dejó este verbo en su breve trayectoria medieval:

...per illa fonte de Ameneiro... et inprona ad ille pumar de Bauzolinas et trauce ille fontano de Almafalla (año 9o 7 ; $P M H$, t. 15, p. 10, citado, como el ejemplo siguiente, por Menéndez PIdAL, ed. Cantar de mio Cid, p. 871); et si trocierit illo die (Fuero de Logroño, año 1095; ap. T. MUNoz y Romero, Colección de fueros municipales y cartas pueblas, Madrid, 1847 , p. 338); ...leuáronse homines de Bonille cum suo ganato e trocieron Aslanzón... Et si trociese ganado de Boniel a Aslanzón, si trociere bez de bacas, che coman la uaca, et de grege de ouegas, che comant carneros, et de uez de puercos, co[mant] porcos (Documentos lingüisticos de España, t. 1: Reino de Castilla, ed. Menéndez Pidal, Madrid 1919[-21], núm. 147, año 1100, Frandovínez o Buniel, pueblos situados unos 12 kilómetros al Oeste de Burgos)²; los seys días de plazdo pasados los an, / tres an por troçir, sepades que non más (Poema de mio Cid, ed. Menéndez Pidal, vs. 3o6-307); troçen las Alcarrias e ivan adelant (ibid., 543); troçieron a Santa María e vinieron albergar a Fronchales (ibid., 1475); hivan troçir los montes, los que dizen de Luzón (ibid., 2653); troçieron Arbuxuelo e llegaron a Salón (ibid., 2656); teniendo iva armas al troçir de Salón (ibid., 2687)3; troçieron Alçoçeva, adiestro dexan Gormaz (ibid., 2875) ${ }^{4}$; troşida es la noche, ya crieban los

${ }^{1}$ Francisco de Ávila, Diálogos en que se trata de quitar la presumpción y brio al hombre..., Alcalá, 1576 , f. 55 : “... y no de una generación, sino de muchas, de girgueros, oropéndolas, calandrias, ruyseñores, sin otra infinidad que truce por el ayre y haze bolando más fiestas..." (F. Rodrf́guez Marín, Dos mil quinientas voces..., Madrid, 1922, p. 386 ).

2 Debo esta cita a V. R. B. Oelschläger, A medieval Spanish word list, Madison, 1940, pp. 207b, 208a. Sobre trociese ver en especial Menéndez Pidal, Origenes del español, Madrid, 1926; $2^{\sharp}$ ed., 1929, p. $3^{83} ; 3^{x}$ ed., 1950, p. 366 (\$ 75s).

${ }^{3}$ Pero el v. 1228 reza: "En el passar de Xúcar i veriédes barata"; obsérvese la misma alternancia de pas(s)ar y troçir en los vs. 306-307.

* Este ejemplo falta en el Vocabulario de Menéndez Pidal; lo trae J. D. M. 
albores (ibid., 3545); las noches e los días ý los querría troçir, / por salvar la su alma... (Berceo, La Vida de Santo Domingo de Silos, ed. Fitz-Gerald, mss. E, H, *V, 91c); maguer tornó en cabo en todo su sentido, / regunzó al convento por qué auié trocido (Milagros de Nuestra Señora, ms. I, ed. Solalinde, $178 \mathrm{~cd}$; ms. A, ed. Marden: E declaró al convento por qué auja troşido; cap. 7: "El monje y San Pedro")5; los vienes que fiziera ennos tiempos troçidos / el buen Sennor non quiso que li fuessen perdidos (ibid., ms. I, 749ab; ms. A: Los bienes que fiziera en los tienpos troçidos; cap. 24: "El milagro de Teófilo")6; et de todas las noblezas uos quesiemos dezir, / ante podrién .x. días e .x. noches troçir (Libro de Alexandre, ed. Willis, ms. O, 1501ab; ms. P: que de todas sus noblezas vos queramos dezir, / antes podrían tres días e tres noches torçir [se trata de una copia tardía, de hacia 14001); metiósse en las naues el Rey aperçebido, / ovo a poca d'ora al Adapis troçido (ibid., ms. O, $2038 \mathrm{~cd}$; ms. P: Ovo en poca de ora a Danprisis troçido); troçir luego ad África conquerir a esas gentes (ibid., ms. O, 2461a; ms. P: troçir luego a África, conquerir estas yentes); ancho era e fondo, non lo podién troçir (ibid., ms. O, $2164 c$; ms. P: Ancho era e fondo, no lo podian troçir $^{7}$; el conde don Yllán, byen auedes oýdo, / cómmo ouo por las paryas a Marruecos trocido [ms.: commo auedes... a Maruecos torçido] (Poema de Fernán González, ed. Marden, 42ab) .

Estos ejemplos muestran que trocir, en general, era transitivo, pero a veces compartía las funciones de un verbo intransitivo (de tres veces dos en el documento burgalés del año 1100 , siendo sujeto ganado o bez de bacas 'tropel de vacas', y en los textos poéticos, hablando del tiempo o del movimiento de un ejército). Semejante dualismo sintáctico también caracteriza el empleo de su sinónimo pas(s)ar en todos los romances que han adoptado este vulgarismo latino muy tardío (no penetró en territorio rumano, donde se usa en esta acepción trece, de t $\mathrm{r}$ à i c e r e, formación gemela de $\operatorname{trā} d \bar{u}$ c e re). No sería de extrañar que trocir,

Ford, “Old Spanish etymologies", $M P h, 5$ (1903-04), 54-55, y tras él OelschläGier en su edición escolar del Poema (New Orleans, 1948), p. 121.

5 Traducción de Solalinde: 'por qué había pasado'. Llama la atención que T. A. Sánchez, de ordinario muy perito en determinar los significados, traduzca trocir en este pasaje por 'morir, pasar', tal vez bajo la impresión de transido 'muerto' (Vida de Santa Oria, 165 b) que figura en la misma página de su Glosario, o infiriendo ese sentido del contexto (se trata de un resucitado); cf. Poesias, t. 2, Madrid, 1780 , p. 555. Ya en el tomo siguiente trata de salvar el error (p. 438): trocir 'pasar, atravesar', el cual, sin embargo, se desliza en muchas obras posteriores, hasta la última edición (1956) del Diccionario académico; cf. infra, notas 11 y 14. Sobre esp. ant. regunzar ver la noticia provisional en $P h Q, 24$ (1945), 249-251.

- Sánchez y F. Janer también leyeron troçió en Milagros, $3^{8} b$ (cap. 17: "La iglesia profanada"), lección que se perpetúa en la subsiguiente literatura sobre trocir y trozo, pero el texto que ofrece Solalinde sustituye troció por trovó 'encontró', enmienda tanto más feliz cuanto que el contexto favorece tal interpretación y que trovar era verbo muy común en antiguo navarro-aragonés, incluyendo al subdialecto riojano: "El que yva fuiendo con mui grand pavor / trovó una eglesia, ovo end grand sabor" (el ms. A, castellanizado, reemplaza trovó por falló).

${ }^{7}$ No se ocupó de este verbo A. Morel-Fatio en el Glosario que forma parte de sus "Recherches sur le texte et les sources du Libro de Alexandre", Ro, 4 (1875), $7-90$, en particular p. $5^{1}$, y lo menciona muy sumariamente J. Keller en su Vocabulario.

${ }^{3}$ Siguen a Marden (1904) Zamora Vicente (1946) y R. Meníndez Pidal, Reliquias de la poesia épica española, Madrid, 1951, p. 39 . 
voz ya caduca durante los siglos x-xin, debiese tal extensión de su función primaria (presumiblemente transitiva) a la larga coexistencia del pujante neologismo passar, dado el perfecto paralelismo de ciertos matices semánticos en los dos verbos rivales ${ }^{9}$. Es notable que trocir casi siempre significa 'salvar, atravesar un obstáculo' (un río, un estrecho o una sierra); metafóricamente, 'soportar dificultades, tener experiencias' (así en Milagros, $178 d$ ). En unos pocos casos, sobre todo en sentido temporal, la visión del obstáculo se ha borrado por completo.

Este análisis preliminar nos ayudará a orientarnos en las tentativas relativamente escasas de interpretación etimológica ${ }^{10}$. Dejando a un lado el disparatado conato de Lanchetas de asociar trocir con tr u x, t r u c is 'violento, feroz, salvaje'11, cabe subrayar la importancia del feliz hallaz. go de T. A. Sánchez, no sólo por haber dado este erudito con una solución nueva y muy digna de nuestra atención, sino por haberla formulado con una elegancia que honraría a cualquier romanista de comienzos de nuestro siglo: "La forma de trocir es muy clara. Perdida la $d$ de t $r \bar{a} d \bar{u}$ c e re, como se ha perdido en otras muchas voces pasando del latín al castellano, se formó traucir: convertido o pronunciado el au como $o$, trocir" 12 . A esta conjetura se adhirieron sin vacilar Diez, Körting y Meyer-Lübke en sus diccionarios etimológicos ${ }^{13}$, Menéndez Pidal en su vocabulario (19o8) del Cantar de mio Cid (p. 871) y otros eruditos que representan gran variedad de preparación científica y de gusto personal en materia lexicológica ${ }^{14}$.

${ }^{9}$ Tal paralelismo abarca incluso el sentido 'tragar', de especial interés para nosotros. Así PéRez Galdós, Misericordia, cap. 6 (ed. 1897, p. 55): “¿Qué ha tomado? ¿El poquito de cocido que le aparté anoche? - Hija, no pude pasarlo”.

${ }_{10}$ Trocir, excluído de las primeras ediciones del Dicc. Acad., tampoco está representado en C. MichaËLIs [DE VAsCONCELOs], Studien zur romanischen Wortschöpfung, Leipzig, 1876 , p. 299, donde figuraría sin duda de haberlo considerado la autora como doblete del cultismo traducir, dada la presencia de la bifurcación semántica que ella usó como criterio. Tampoco parece que se hayan ocupado de este verbo G. BaIsT en Die spanische Sprache ( $2^{n}$ ed.), C. von Reinhardstoettrner, P. Förster, E. Gorra, J. J. Nunes y F. Hanssen en sus respectivas gramáticas históricas del español y del portugués, A. Horning y J. Saroïhandy en sus estudios sobre las sibilantes, ni MEYerLÜBKE en su monumental gramática comparada o en su sustancial reseña de la tesis de Ford, $L G R P h, 22$ (1901), cols. 297-298. No registran el verbo ni Cabrera ni Monlau.

11 Seducido por la metáfora matar ('pasar') el tiempo y confundiendo los ámbitos semánticos de trucīdō, -āre 'matar' y trux, -cis 'salvaje', R. Lanchetas, Gramática y vocabulario de las obras de Berceo, Madrid, 19oo, pp. 756-757, es también víctima de una tercera ilusión: de que trocir en lo antiguo significaba ocasionalmente 'morir', error que, según consta, se remonta a Sánchez y que desgraciadamente reiteraron Difz y sus secuaces inmediatos. La $12^{\text {a }}$ ed. del Dicc. Acad. (1884) atribuyó a trocir (dudo de que con razón) el doble significado de 'pasar, cumplir', sin llegar a una conclusión etimológica.

12 T. A. SÁnchez (ed.), Colección de poesias castellanas anteriores al siglo xv, t. 1, Madrid, 1779 , p. 402. A la luz de las pesquisas ulteriores de Menéndez Pidal en documentos notariales, la forma intermedia traucir reconstruída por Sánchez queda brillantemente confirmada.

${ }_{13}$ F. Difz, Etymologisches Wörterbuch der romanischen Sprachen, Bonn, 1853 , p. $54^{2} ; 3^{a}$ ed., t. 2, Bonn, 1870 , p. 188 ; G. Körting, Lateinisch-romanisches Wörterbuch, Paderborn, 1891, núm. 8293; $2^{9}$ y $3^{a}$ eds., Paderborn, 1901, 1907, núm. 9655 , con inexacta grafía de port. traduzir; $R E W^{1}$ y $R E W^{3} 88_{31}$, con traducción correcta sólo en parte ('vorbeigehen'; Dirz, mejor conocedor de las fuentes medievales, prefirió 'hindurchgehen', al cual se podría agregar 'vorübergehen', hablando del tiempo).

I4 Basta con citar a J. Cejador y Frauca, Vocabulario medieval castellano, Ma- 
Sin embargo, la hipótesis de Sánchez no fue aceptada con unanimidad. Entre los críticos escépticos, agnósticos o francamente hostiles figura Ford, quien ya en 1897 protestó contra la derivación, afirmando que el producto ideal de $\mathrm{t} r \overline{\mathrm{a}} \mathrm{d}$ ù c e re hubiera sido *trozer, no troşir, y llamando la atención sobre la variante torcer en el manuscrito escurialense (siglo xv) del Poema de Fernán González (no se había publicado todavía la versión aragonesa del Libro de Alexandre $)^{15}$. A los pocos años, combinando estas dos observaciones sueltas y agregando el argumento de que $\mathrm{trādūcere} \mathrm{de} \mathrm{todos} \mathrm{modos} \mathrm{había} \mathrm{producido} \mathrm{traduzir} \mathrm{en}$ español medieval ${ }^{16}$, Ford postuló to rquēre, lat. vulg. *t o r cēre como base de trosiriti. El único filólogo, salvo error, que apoyó este

drid, 1929, p. 396a; a la Academia Española, que en los últimos decenios sigue en su Diccionario la norma de J. Alemany Bolufer y que, a su vez, sirvió de modelo a A. de Pagés y J. Pérez Hervás, Gran diccionario, t. 5, p. 568a; a A. Zamora Vicente, ed. Poema de Fernán Gonzillez, p. 12, que invoca la autoridad de Menéndez Pidal; a R. S. Boggs, L. Kasten, H. Keniston y H. B. Richardson, Tentative dictionary of medieval Spanish, Chapel Hill, 1946, p. 5og, que desgraciadamente se empeñan en mantener la falsa interpretación de trocir en Milagros, 178 (véase supra, nota 5); a V. R. B. Oflschläger, ed. Poema del Cid, p. 121, quien se refiere a un artículo mío en $H R, 14$ (1946), 106, n. 3 (sin reparar en lo hipotético de mi formulación). V. Garcfa de Drego, Gramática histórica española, Madrid, 1951, pp. 59, 73. Examino el problema con mayor detenimiento en PhQ, 29 (1950), 163, n. 41. También da su asentimiento del Marqués de Valmar en su edición de las Cantigas de Santa Maria, Madrid, 1889 , t. 2, p. $786 a$ (jsegún el cual trocir entronca con el verbo galorrománico traucar!).

${ }^{15} \mathrm{~J}$. D. M. Ford, The Old Spanish sibilants. El trabajo salió más tarde en [Harvard] Studies and notes in philology and literature, 7 (1900), 77. E1 autor califica troçir de vocablo "de origen oscuro".

${ }_{16} \mathrm{Al}$ ejemplo que trae Ford (traducción de la Iliada, ed. Vollmöller, en Studien zur Literaturgeschichte, Michael Bernays gewidmet, Hamburg, 1893, p. 238, 1. 8) se podrían agregar otros varios. Sin embargo, importa recordar que el equivalente principal de 'traducir' en la lengua medieval era tra(s)-, tre(s)-ladar, cf. ingl. to translate; además tenía vigencia, en sentido más restringido, romançar 'romancear'.

${ }_{17}$ "Old Spanish etymologies", $M P h, 1$ (1903-04), 54-55. Para el desarrollo semántico Ford aduce el presunto paralelo de ingl. went [frente a al. wenden]. Justifica el paso al paradigma verbal de -ir por el influjo de $(\mathrm{t} r a \bar{n} \mathrm{~s}) \overline{\mathrm{r}} \mathrm{e}$. Pero no cuida de explicar la relación de trocir con torcer, que debería ser el punto central de su demostración. Y al basar su hipótesis en una sola lección del Poema de Fernán González, parece no darse cuenta de que trocir, ya ausente de Calila y Digna (según C. G. Allen y R. M. Pérez), de las obras de don Juan Manuel (según F. Huerta Tejadas), de Juan Ruiz (según H. B. Richardson), del Poema de Alfonso XI (según Y. ten Cate) y del Rimado de palacio (según la tesis inédita de M. A. Zeitlin), forzosamente fue estropeado por un copista del siglo Xv (así fechan el ms. Esc. b. iv. 21 Marden en 1904 y González Llubera en 1947). Por otra parte, no deja de ser curioso el cambio en dirección opuesta que sufrió retorcer en alto aragonés: retrocé 'torcer' (Ansó, Hecho), frente a retorciú 'irregularidad en el hilo' (Hecho), según A. K.UHN, RLiR, 11 (1935), 164. Parece que la hipótesis de Ford, rotundamente rechazada por Meyer-Lübke ("en lo semántico más difícil y en lo fonético no más sencilla"), tampoco satisfizo del todo a su autor. En el glosario etimológico que acompaña sus Old Spanish readings selected on the basis of critically edited texts, Boston, 1911 (no hay enmienda en las Correcciones de la ed. de 1939) ya es mucho menos categórico (p. 302b: < trā d ū cere? t orquēre?). Problema muy distinto del genético sería el de averiguar si en su última etapa de decadencia y disolución tro-, tru-cir se confundió con verbos de aspecto semejante, como torcer, trozar, etc. y fue absorbido por ellos. En este respecto me parecen notables el giro esp. ant. torcer la via y el siguiente dato que trae F. J. CAvadA, Apuntes para un vocabulario de provincialismos de Chiloé, Punta Arenas, 1910, p. $137 b$ : tronchar, trozar 'dirigirse para un lado, torcer hacia algún punto'. 
étimon fue Huber ${ }^{18}$. Tallgren, a quien se le pasó por alto el verbo en su primer estudio sobre las sibilantes, quizás por falta en la Gaya (siglo xv) ${ }^{19}$, en su segunda monografía reprochó a Marden el haber reconstruído troçir y no [*] trozir (nótese el contraste con Ford en la selección de la base ideal), "si es que deriva de t $\mathrm{r}$ à d ù c e r e" ${ }^{20}$. Nobiling acopló esp. ant. trocir con gall. ant. trocir 'tragar' (Cantigas de Santa Maria), sin decidirse en favor o en contra de la conjetura ${ }^{21}$. Cuervo guardó silencio sobre el abolengo de trocir en las dos redacciones de su estudio sobre "Antigua ortografía y pronunciación castellanas", tal vez porque Nebrija excluyó el verbo de su diccionario, punto de partida del nuevo examen; pero al hablar del Poema del Cid reconstruído por Vollmöller, agrupó trocir con dice 'baja', de decir'22.

Entre los defensores de la derivación clásica trocir $<\mathrm{t} r \mathrm{a} \mathrm{d}$ ū c e re, A. Gassner no agrega nada esencial a lo ya anticipado por Tomás Antonio Sánchez y además complica las cosas, puesto que opera inútilmente con trānsdūcere en vez de adherirse a trä dūcere, olvidando la variante muy común $\operatorname{tr} \bar{a}-$ de $\operatorname{tra}(n) s-$ ante consonante sonora ${ }^{23}$. Mucho más valioso es el comentario de Menéndez Pidal ${ }^{24}$ : equipara trocir (jamás *trozir) a poco $<\mathrm{paucu}$, sope $<\mathrm{sapui}$, sepa $<\mathrm{sa}$ piat, frente a yogo < i a cuit, plogo < placuit, es decir, da por sentada la acción conservadora de la semivocal [w] -comparable a la de cualquier consonante antecedente- sobre la velar asibilada [k], que contrarresta la tendencia latente a la sonorización. La dificultad de la hipótesis es cronológica, no articulatoria: si [w] impidió la sonorización, hay que contar con la caída de la $d$ intervocálica latina y la contracción de la $a$ anterior y la $u$ posterior en un solo diptongo decreciente $[\mathrm{aw}]$ en fecha particularmente temprana, que anteceda a la sonorización de las oclusivas sordas. Este orden cronológico, ya difícil de por sí, dada la fecha marcadamente remota que atribuyen a la sonorización W. von Wartburg y otros especialistas, se hace inverosímil en este caso

${ }_{18}$ J. Huber, Altportugiesisches Elementarbuch, Heidelberg, 1933, p. 132, $\S 284 b$, sin referirse a Ford.

19 O. J. Tallgren [-Tuulio], "La $z$ y $c$ del antiguo castellano iniciales de sílaba", Mém. de la Soc. Néo-philol. de Helsingfors, 4 (1906), 1-50, 397-401.

${ }^{20}$ Estudios sobre la "Gaya" de [Pero Guillén de] Segovia, Helsinki, 1907, p. 84, nota 1. En el mismo contexto se menciona deçir 'bajar', que el autor deriva de dēc i d e re.

${ }^{21}$ O. NobILING, "Berichtigungen und Zusätze zum portugiesischen Teil von Körting's Lateinisch-romanischem Wörterbuch", ASNS, 127 (1911-12), 375; nota que tuvo muy en cuenta Meyer-Lübke.

22 R. J. Cufrvo, RHi, 2 (1895), 26 y en el pasaje correspondiente de Obras inéditas, Bogotá, 1944, p. 417 .

${ }^{23}$ A. Gassner, Das altspanische Verbum, Halle, 1897 , p. 33. Menciona la discrepancia entre ado-, adu-cir y trocir sin tentativa de explicación. Para ejemplos de verbos compuestos convertidos en verbos simples (començar, comer, res- y ras-gar), véase UCPL, 11 (1954), 69-71 (repudiāre) y BICC, 9 (1953-55), 116-117 (benedic t u s) y 119 (variantes de be-hetria, de remoto origen verbal).

${ }_{24}$ Ed. Cantar de mio Cid, $\S 36_{1}$ (con cita de J. Lette De Vasconcelos, Estudos de filologia mirandesa, t. 1, Lisboa, 1900, p. 215, donde distingue los diptongos primarios de los secundarios (causados por metátesis), sin asignar lugar aparte a los terciarios, producidos por la caída - forzosamente más tardía- de una consonante; y $\$ 30_{1}$, con acertado análisis de la "antiquísima" dislocación del acento. Lástima que no haya discutido este problema A. Aronso en sus Cambios acentuales (1930). 
concreto por varias circunstancias. $\mathrm{S}$ a b $\overline{\mathrm{u}} \mathrm{c} u>$ esp. saúco muestra la chocante conservación de la sorda entre vocales, dificultad que Aebischer resuelve presuponiendo la propagación de una forma aragonesa hacia el Oeste, mientras otros optan por el juego de los sufijos -aco y -ago, $-(i) e c o$ y -(i)ego, -uco y -ugo, etc. ${ }^{25}$ Pero nadie puede pensar en la contracción de - a b ù- en [aw] como causa del retraso, por faltar en lo antiguo las variantes *sáuco, *soco ${ }^{26}$. Además, la caída de la $d$, normal en gallegoportugués, no lo fue en grado comparable en castellano (alternan nio y nido, frio y frido, etc.), de modo que es sumamente improbable que haya precedido a la sonorización de las sordas, regularísima en toda la Península menos una sola zona de Aragón, reducida por lo demás. En fin, dentro de esta familia particular caracterizada por el mantenimiento de aduzir ${ }^{27}$, que los hablantes no podían menos de asociar largo tiempo con traduzir, la caída de la - $d$ - debió de atrasarse más bien que de adelantarse, por motivos de orden léxico.

Merece especial atención gall. ant. trocir, a que aludió ya Nobiling, señalando su peregrino significado de 'tragar', es decir, pasar por la garganta, vista como una especie de desfiladero. He aquí los tres ejemplos que consiguió descubrir el Marqués de Valmar en las Cantigas de Santa Maria $^{28}$ :

Ca o rostr'e a garganta ll'enchara / et o coiro fendera-ss' e britara, / de maneira que atal se parara / que non podia trocir a taulinna (Cant. 57, estr. 7); e o crérigo, sen arte, / de a comungar coidou; / mai-la ostïa na boca / aquesta moller guardou, / que per nehũa maneira / non a trociu nen passou (Cant. 104, estr. 5); ca u meteu a agulla / na boqu'e, endereçando / as peles pera lavrá-las, / non catou ál senon quando / a trociu

${ }^{25}$ Sobre los últimos aportes de D. Alonso, P. Aebischer y G. Bonfante a la discusión de este problema, ver mi artículo "Studies in Spanish and Portuguese animal names" (I), HR, 24 (1956), 135-141.

${ }^{26}$ Nótese el dictamen de A. Horning, reseña de la tesis de Ford, ZRPh, 26 (1902), 361, a propósito de cadoço: "Ca dū cius hubiera producido "caucos" (es decir, agrego por mi cuenta, no *coşos). No discuto el aspecto fonético de cat. rautar 'raer' $<\left[{ }^{*}\right]$ rāditā re (L. SPItzer, "Etymologisches aus dem Katalanischen", NM, 1919, núms. $5^{-6}$, p. ${ }^{176}$ ) por tratarse de una ecuación totalmente errónea (ver MEYERLÜBKE, $R E W^{3} 69^{8} 7$ ).

${ }_{27} \mathrm{Si}$ Körting no hacía el menor esfuerzo por separar las voces patrimoniales de los cultismos, Meyer-Lübke llegó al otro extremo, trazando límites demasiado rigurosos entre las categorías sociales. Así, port. traduzir, esp. traducir resultan clasificados en su diccionario como voces eruditas, mientras port. aduzir, esp. aducir (REW $W^{3}$ 160) figuran como voces heredadas directamente del latín coloquial. De hecho, entre lo estrictamente culto y lo realmente popular conviene suponer varias capas intermedias (para servirnos de la metáfora estratigráfica). Dentro de esta jerarquía matizada, a los productos de a d d ū c e re les corresponden rangos distintos en las diferentes lenguas y aun en cada lengua según el período: port. ant. aduzer (J. Cretella JúNIOR, "Dicionário do português arcaico", $J F, 3,1955,119^{-120}$ ) es más castizo que port. mod. aduzir, que a la vez se acerca a los cultismos y a las voces tomadas del castellano; notable paralelo semántico: en bajo latín hispánico el verbo se usaba en acepciones que ignora el idioma moderno (Documentos lingüisticos de España, núm. 147; Origenes del español, $3^{*}$ ed., $\S 75_{4}$ ). La alternancia de aduzir y adozir es resultado indirecto del consabido titubeo entre complir y cumplir, contir y cuntir, nozir y nuzir y varios otros verbos (A. ZAUner, Altspanisches Elementarbuch, $2^{\mathrm{a}}$ ed., Heidelberg, 1921, p. 79).

zs Retoco ligeramente la puntuación y acentuación de estos tres trozos. El editor se contenta con traducir el verbo por 'pasar, atravesar', remitiendo al lector a 
e na garganta f se lle foi atravessando (Cant. 191, estr. 4; se trata del milagro del peletero).

Más notable que la especialización semántica me parecen un rasgo fonético: la falta del diptongo -ou-, reflejo normal de -au- latino y postlatino en gallegoportugués, y otro morfológico: el puesto que ocupa trocir entre los verbos del tipo -ir y no -er, frente a port. ant. aduzer, etc. A la única peculiaridad que obsta en castellano a la derivación de trocir $<\mathrm{trā}$ d ū c e r e se agregan así otras dos en la zona occidental. Verdad es que trocir podría representar un préstamo, pero a esta altura no se ve a las claras el motivo para tal proceso de difusión.

Ahora bien: ya a fines del siglo xvin el benemérito frey Joaquim de Santa Rosa de Viterbo señaló el arcaísmo trouşar 'pasar, vencer, exceder' (las variantes trouciar, trouxiar son obvios ejemplos de grafía latinizante ${ }^{29}$ ) que en ciertos textos jurídicos alternaba con passar a lo largo de los siglos xII y xIII ${ }^{30}$. A mí me parece que trouciant, por lo menos en el ejemplo citado, representa un subjuntivo que permite reconstruir un infinitivo *troucer o *troucir (a lo sumo *trouzer, cf. fasa < $\mathrm{faciat} \sim$ fazer $<\mathrm{facere).} \mathrm{No} \mathrm{prestó} \mathrm{atención} \mathrm{a} \mathrm{este} \mathrm{importante}$ detalle J. M. Piel al definir este verbo mal transcrito, a la zaga de C. de Figueiredo y sin consultar las fuentes primarias, "pasar adelante, tener la primacía, ser más atendido' y al equipararlo a gall. ant. trocir 'tragar', a port. ant. trocir = lat. deglutio (glosario medieval, ms. Alcobaça 404) y a miñ. trouscar 'trasegar', trouça 'trasiego' ${ }^{31}$. A mi modo de ver, es arriesgado e inútil reconstruir, a base de una sola forma moderna limitada a una estrecha zona dialectal (desde luego, doy por descartado port. ant. trouçar) el prototipo lat. vulg. * t rä d u c t i āre, proyección que nadie reprobaría con mayor severidad que Max L. Wagner ${ }^{32}$. Es perfectamente concebible que port. ant. trou-cir (o-cer) $>$ miñ. trousar

J. Cuverro Piñol, Diccionario gallego, Barcelona, 1876 , quien traduce a simismo trocir (ant.) 'pasar'.

29 Así me explico también el famoso mentiriosus de la glosa latina; ver $R P h, 6$ $(1952-53), \quad 121-172$.

${ }_{30}$ Viterbo, Elucidário das palauras, termos e frases..., 2" ed., Lisboa, 1865 , t. 2, p. 261 b: "In juramento trouciant super illos cum dous juratores... stent et trouciant super illos cavaleiros villanos de totas alias terras in judicio" (Foral de Linhares da Serra da Estrela, otorgado por D. Afonso Henriques, primer rey de Portugal), frente a "et passent super illos cum duos juratores" (Foral de Aguiar da Beira, año 1258, otorgado por D. Afonso III, Doações, lib. I, f. $\left.33 \mathbf{v}^{0}\right)$.

${ }^{31}$ J. M. PIEL, "Etimologias portuguesas", núm. 10, Bs, 20 (1944), 130; reimpreso, sin correcciones ni agregados, en Miscelânea de etimologia portuguesa e galega, t. 1, Coimbra, 1933, pp. 304-305; cf. B. Pottrer, Ro, 73 (1952), 287. En 1944, Piel extrajo la ecuación trocir $=$ deglutio de un glosario medieval transcrito por Maria do Céu Leitão Nogueira, pero entonces todavía inédito; este texto, transcrito independientemente por H. H. Carter, según fotocopia de E. B. Williams, y publicado ahora en $R P h, 6$ (1952-53), $71-103$, con índice alfabético, contiene, además de trocir $=$ deglutio (núm. 749), la ecuación paralela trucir = transglutio (núm. 2765 ). La variante trucir, con el vocalismo de cundir, cumplir, etc., aparece esporádicamente en el español del siglo Xvi (véase supra, nota 1).

${ }^{32}$ Véanse sus artículos, en parte redactados en tono polémico, "Betrachtungen über die Methodenfragen der Etymologie", CuN, 3 (1943), 5-26; "Os nomes da 'moega" nas línguas ibero-românicas", Bs, 24 (1948), 247-265, y sobre todo "Etymologische Randbemerkungen zu neueren iberoromanischen Dialektarbeiten und Wörterbüchern", 
represente un sencillo cambio de conjugación que no sería difícil de explicar $^{33}$. Lo curioso es que entre el acto de trasegar, mediante un em. budo, y el de tragar (cf. esp. fam. trasegar, colar 'tragar') hay cierta semejanza muy sugestiva, principalmente en cuanto ambos denotan movimiento vertical, mientras esp. ant. trocir 'atravesar (un río, una sierra, una dehesa)' se refería a un movimiento horizontal o, cuanto más, sesgado.

Me parece que la grafía arcaica trauce recogida en un texto lusolatino (año 907), que sería forzado explicar por ultracorrección, el port. ant. trouc-er o -ir del siglo XII (disfrazado como trouçar en el Elucidário de frey J. de Santa Rosa de Viterbo y en las compilaciones posteriores) y miñ. trouçar, acompañado del sustantivo trouça (cualquiera que sea la causa del cambio de conjugación), abogan en favor de la vieja etimología que Sánchez estableció por feliz intuición, sin tener a mano todos los eslabones intermedios. Además me inclino a creer que gall.port. ant. trocir, trucir, con su chocante monoptongo, puede ser un antiquísimo préstamo tomado del leonés, tanto más comprensible cuanto que en cierto modo el verbo expresaba la actividad esencial de los pastores trashumantes que nunca respetan fronteras dialectales. No me parece lícito rechazar a priori la idea de que el matiz privativamente occidental de 'tragar, bajar' (cf. fr. a-val-er 'hacer bajar, tragar, comer o beber ávidamente, comer sin masticar', de fr. ant. val $<\mathrm{u}$ a $11 \mathrm{e}$, en el sentido de 'angostura') haya existido, al margen del sentido central, también en leonés antiguo y hasta en variedades del castellano preliterario, ya que los escasos textos españoles que ofrecen trocir a lo sumo nos hacen entrever algunos empleos estereotipados por la poesía épica o por los documentos notariales. El único obstáculo estriba en la incompatibilidad fonética de trocir y $\mathrm{t} \mathrm{r}$ à d ūcere, étimon apoyado, a su vez, por la vigencia de los productos romances de trād uc tus, -a (participio usado a manera de sustantivo y dle adjetivo) y de $\operatorname{tr} \bar{a} \mathrm{~d} u x$,

$Z R P h, 69$ (1953), 347-391, cuyos méritos y defectos comenté en $R P h, 9 \quad\left(1955^{-56)}\right.$, $50-68$; además, la sustancial reseña de la tesis de $M$. T. de M. Lino Netto en $R P h$, 6 (1952-53), 316-335. Piel se funda en el paralelo fonético y morfológico de " $\mathrm{ra}$ ptiāre (ha de ser errata raptāre), presunto derivado del participio ra ptus, como base de port. ant. rouçar, var. roussar, y la productividad de este radical (r a pter, en glosas, 'martillo grande del herrero'; adv, raptim 'con violencia, de prisa, arrebatadamente'; raptio 'robo', que hasta podría ser base de port. ant. rouçom 'rapto de una mujer', ver $R E W^{3} 7062$; raptor; raptōrius en Celio Aureliano; sust. raptus) apoya su conjetura, que ya formularon con anterioridad Diez y Meyer-Lübke. Pero hay graves inconvenientes fonéticos. Extraña que en 1944 Piel no haya consultado la nota sustancial de G. Trlander, "Rausar, rousar, rouxar, roixar; rauso, rouso, rojo, roxo, roiso", $B d F, 6$ (1939-40), 188-197, quien a la zaga de G. Gröber y a base de un material exhaustivo extraído de textos fechados y bien localizados, reconstruye los verbos gemelos lat. vulg. provinciano * $\mathrm{r}$ a $\mathrm{p}$ s a $\mathrm{re}$, $\mathrm{r}$ aps i a re, característicos de todo el Occidente de la Península. El punto de arranque sería el part. pas. ra psus, variante atestiguada en inscripciones y usada por el autor anónimo (presumiblemente hispanolatino) de la obra De bello Africano. Para nosotros lo interesante es que rousar, rouxar, etc. no aparecen más que en textos jurídicos (Tilander los designa como semicultos), igual que port. ant. trouc-er o -ir que clasificó equivocadamente el compilador del Elucidário.

${ }^{33}$ Por ejemplo, suponiendo que trouçar es derivado de trouça, a su vez última reliquia (derivado posverbal) de troucir; u operando con cruces de palabras. Perpetuaron el error frey Domingos Vieira y otros lexicógrafos portugueses. 
-c i s 'mugrón de la vid' ${ }^{44}$. Tal dificultad se reduce, en rigor, a la - 5 sorda frente a la -z-de $a d u$-, ado-zir, no-, nu-zir, etc. ${ }^{35}$

¿Se trata quizá de un juego de analogía léxica? Faltan todos los requisitos (afinidad semántica, jerarquía de frecuencia) para que esp. ant. troço, destroçar, cualquiera sea su etimología ${ }^{36}$, hayan podido ejercer el menor influjo sobre el carácter de la sibilante. Por otra parte, sí me parece verosímil que esp. ant. deçir 'bajar', de marcada vitalidad (superior a la de troçir) a lo largo de la Edad Media, de parecido ámbito

ss La derivación de trocha 'sendero' (ya en la Comedieta de Ponza) de t $\mathrm{r} a ̄ \mathrm{~d} u$ c $\mathrm{t}$ a se debe a J. Corominas, "Dis Aup i Pirenèu", Sache, Ort und Wort: Festschrift für Jakob Jud, Zürich, 1943 , pp. 564-565. Cf. atrocharse sant. 'meterse en una trocha' (J. M. DE Cossío), segov. 'decidirse, atreverse' (G. M. Vergara Martín), cabr. entrochar 'agradar', quizás < *'tratar de engañar' (S. Alonso GARRote), alav. trocho 'travieso, malo, de torcidas intenciones' (F. BARÁIBAR Y ZuMÁrRAGA) y la serie andaluza trocha (echar, tomar por la...) 'atajo, calle de en medio', 'defecación de conejo o liebre que señala al cazador la presencia de estos animales' [es decir, le muestra la senda], trochar 'atrochar', trocheria 'tontería, embuste', trocho 'individuo que dice tonterías', trochón 'desarreglado' (A. Alcalá VencesladA, 1951). Tal vez trochar, que ya figura en el Corbacho, f. $27 \mathrm{r}^{\circ}$ y, dentro de la misma zona dialectal, en la anónima Éloga pastoril valenciana (vs. $726-728$ ) recogida por E. KoHLER en su miscelánea, representa el punto de arranque. Sobre la presunta familia de $t \mathrm{ra} a \mathrm{~d} u x$, - $\mathrm{c}$ i s ver $P h Q, 29$ (1950), 153, 162; estudio detenidamente el modismo a trochemoche (trochimoche) en mi monografía (en preparación) The Hispanic verbs for 'shearing'.

${ }_{35}$ Ya repararon en lo característico de esta $z$ C. JORET, Du $C$ [latin] dans les langues romanes, Paris, 1874 , cap. 7 , donde opuso trocir (sin etimologizarlo) a aduzir; y A. Horning, Zur Geschichte des lat. $C$ vor $E$ und I im Romanischen, Halle, $188_{3}$, p. 86, quien supo distinguir aduzir y fazer patrimoniales de los cultismos dócil y fácil.

${ }^{36}$ Para la demostración de que destroçar puede explicarse satisfactoriamente como producto de *dēstructiāre, y troço como un caso de regresión, ver $P h Q, 29$ (1950), 151-171. Algunos agregados: (a n. 5) ast. estrociar 'destrozar' en C. CABAL, L'albori de los malvises, Oviedo, s. a., p. 3o; (a n. 6) A. DE LA TORRE, "El habla de Cuéllar (Segovia)", BAE, 31 (1951), 139, también documenta estrozar 'destrozar'; (a n. 8) para un ejemplo de arag.-val. destroza 'destrozo' ver C. Torres Fornés, p. 26oa; (a n. 9) col. bailar un destrós, destrozo 'vals' (R. URIBE U[RIBE], Diccionario abreviado, Apéndice, p. $304 a$ ) ha de representar un curioso disfraz de estráus, es decir, Strauss (cf. Wagner, Mozart, pronunciados a la francesa por los porteños semicultos); (a n. ii) trae ven. trozarse L. Alvarado (1929), p. 442; (a n. 18) reanuda la discusión de it. trozza P. BARBier en su nota póstuma sobre fr. med. tac en $R P h$, 9 (1955-56), 9; (a n. 23) sobre soutroz(o) 'pieza de hierro que impide que caiga la rueda al guiar, en el eje del carro' (Guadalajara), ver G. M. Vergara Martín, Cuatro mil palabras y algunas más, Madrid, 1925 , p. $175^{a}$; no sátisface el comentario etimológico de M. DE Toro y Gisbert, Enmiendas al Diccionario de la Academia, Paris, 19o9, p. 35; (a n. 26) así también fray LuIs de León, Profecía del Tajo, $1_{5}$ e: “Quánto cuerpo de nobles destrozado!”; (a n. 31) la cita de GarcIlaso se refiere a la Égloga tercera, vs. 333-334 (sustituir implacable por espantoso); (a n. 32) troza tiene arraigo en Guinea, según C. GonzÁlez Echegaray, "El español en África ecuatorial", RFE, 35 (1951), 117; pero, lo mismo que troncho, cedió terreno a tronzo en parte del Nuevo Mundo, cf. J. Calcaño, El castellano en Venezuela; estudio crítico, Caracas, 1897, p. 612; (a n. 50) añadir a la bibliografía G. Trlandrr, "Français trousser et trou 'trognon", StN, 16 (1943-44), 185-194: trousser de *torsāre, trozar de *tortiāre, trou de turs u, var. vulg. de thyrsu, cf. M. RoQues, Ro, 7o (1949), 127-128; me explico conq. torozar 'trozar' (J. López BARRERA) por el influjo de tuero, toral, y cost. atorozarse 'atragantarse' (C. GAGINI) por la presión de atorarse; (a n. 54) trozo $\sim$ tirso $\sim$ torso forman una tríada para C. MichAËLIS [DE VASCONCELOS], Romanische Wortschöpfung, Leipzig, 1876 , p. 299 ; (a n. 59) C. Morán, "Vocabulario del Concejo de la Lomba", $B A E$, $3^{\circ}$ (1950), 453, registra leon. touzo 'tronco de leña', si bien su propia frase-modelo contiene touza; (a n. 70) ver Espigueo de latin vulgar, p. 154, n. 1, donde reafirma una idea de García de Diego; (a n. 75) M. T. DE M. Lino Nerto, RPF, 2. (1948), 
semántico y, en parte, sintáctico, de gran arraigo en los propios ambientes dialectales y literarios que favorecían trocir, ya en plena decadencia, haya contribuído con su $-c-$ - [ts] al brote de t r ā d ù c e r e, coadyuvando al triunfo de -ir sobre -er y reforzando el sentido secundario de 'bajar'.

E1 contacto entre los dos verbos pudo establecerse tan sólo en los dialectos centrales, ya que la forma gallegoportuguesa dec-er de por sí no hubiera dado margen a troc-ir, truc-i $r^{37}$. Este factor postulado de difusión, a raíz de la contaminación, lejos de quitar plausibilidad a la hipótesis, condice perfectamente con nuestra observación anterior sobre la $o$ protónica, en vez de gall.-port. ou $<$ a u, y sobre el nomadismo de los pastores que favorecía la infiltración de leonesismos en portugués y viceversa. Además, ya he indicado que tal contacto aclararía un rasgo de la evolución semántica de $\operatorname{tr} \bar{a} \mathrm{~d}$ ù ce re que queda sin explicar: la tendencia, muy marcada en el Oeste y quizás sumergida en el Centro, de interpretar trocir no sólo como 'atravesar, pasar', sino como 'bajar' (en general, por la garganta; en el caso especial de trouçar, por el embudo). ¿Sería demasiado atrevido suponer que, como los pastores leoneses y extremeños, al pasar por las sierras camino de las llanuras del Oeste, de hecho 'descendían', los habitantes de Galicia y Portugal terminaron por generalizar este significado periférico del verbo que repetirían los recién llegados para referirse a su bajada? ${ }^{38}$ En cuanto a la subsiguiente especialización semántica ('deglutir'), ampliamente atestiguada

131, atribuye bajo miñ. atrunchar 'apartar muito de encontro' a la lengua de los pescadores de Vila do Conde.

A esta hipótesis se opone la de J. Huвschmid, "Étymologies romanes: le port. trôço 'morceau' et sa famille", $R P F, 5$ (1952), 1-25 (con análisis de varias conjeturas, incluyendo la de F. KRÜGER, NRFH, 5, 1950, 246-253). Hubschmid, el substratista por excelencia, llega a la conclusión de que port. tróço, esp. trozo, prov. ant. trotz, tros, it. sept. trus se remontan a la base prerrománica ${ }^{*} \mathrm{t} \mathrm{rukio-}$, mientras fr. ant. tros 'pedazo' y sard. truzzu 'cogollo de la berza' ( < it. ant. torzo) son brotes de t u rs u (thyrsu). Me reservo para otra ocasión el análisis detenido del artículo, pero no puedo menos de señalar un error: Hubschmid me atribuye la opinión de que esp. troço surgió después de 1600 (p. 2 de su artículo), mientras en realidad lo rastreo en Juan de Mena (p. 166, n. 43 del mío).

En el oscuro Decir de Juan Alfonso de Baena (Cancionero, núm. 392, f. $139 \mathrm{r}^{\circ}$ II) contra Juan García de Vinuesa, troçedo contrapuesto a maçedo, es decir, m'a $[c] c e d o$ 'me acerco' parece equivaler a 'retrocedo'; creo inadmisible la reconstrucción de un infinitivo [*]troçedar y más la glosa 'trocear' que propone W. Scrmm, Der Wortschatz des "Cancionero de Baena", Bern, 1951, p. 158, trabajo cuyo valor examino en $R P h$, 9 (1955-56), 441-448. Sospecho que can. trusco 'trozo, pedazo (de pan)' que registran L. y A. Millares, Léxico de Gran Canaria, Las Palmas, 1924, p. 184 [muy usado también en México, aunque no aparece en Malaret ni en Santamarf́a], representa un cruce de trozo con churrusco 'pedazo de pan demasiado tostado', que a su vez se relaciona con el grupo churruscar, chamuscar.

${ }^{37}$ Se encuentra deçer en las Cantigas de Santa Maria, núms. $13_{6}, 28_{8}, 113_{3}, 115_{29}$, $121_{5}, 14^{1}, 180_{3}, 19^{1}{ }_{4}, 287_{8}, 318_{1}, 369_{13}$ y en las Cantigas $2^{\mathrm{a}}, 3^{\mathrm{a}}, 4^{\mathrm{a}}$ y $5^{\mathrm{a}}$ de las Festas de Nostro Senhor.

${ }^{s s}$ En cuanto a la etimología de decir, muy debatida a su vez (ver cap. 4 de $\mathrm{mi}$ artículo "The uniqueness and complexity of etymological solutions", que acaba de aparecer en Lingua, 5, 1956, 225-252), me atrevo a remitir a la explicación presentada en Lan, 31 (1955), 291: el latín tardío confundía d ē c ī d e r e 'cortar', de c a ed ere, y de scindere 'hender, rajar', de s cindere (Ernout-Meillet; sobre las pesquisas de Engelbrecht, Löfstedt y Thielmann ver L. SPITzEr, ASNS, 136, $1917,290-298)$; en este proceso acabó por intervenir, por lo menos en territorio hispánico, de éscendere 'bajar', de s ca nd ere 'subir'. 
en Galicia y Portugal en los siglos xirr y xiv, no hay duda de que se deba a un cruce con tragar. Sabido es que una voz importada, de gama semántica fluctuante y amenazada por el poderoso neologismo passar, sucumbe más fácilmente a la contaminación que una voz autóctona y libre de presión ${ }^{39}$.

University of California.

YAKOV MALKIEL

\section{OTRA VERSIÓN DE “SOBRE NEVADOS RISCOS LEVANTADO..."}

Seis son las versiones hasta hoy conocidas de la famosa égloga "Sobre nevados riscos levantado...": I) la del Parnaso español de López de Sedano, t. 4, Madrid, 1776 (de donde pasó a las Poesias de Francisco de Figueroa, ed. Fernández Estala, Madrid, 1804, al t. 42 de la BAAEE y a la nueva ed., por González Palencia, de las Poesías de Figueroa, Madrid, 1943); 2) la de Poesias del siglo xvi, ms. 3968 de la B. N. M.; 3) la de Flores de varia poesía recopiladas en México en 1577, y copia de Paz y Mélia, mss. 2973 y 7982 de la B. N. M.; 4) la de Obras de Mendoza, ms. $425^{6}$ de la B. N. M.; 5) la de Books of poems in Spanish verse, ms. 189 de All Souls College (Oxford); 6) la de Poesias de Pedro Lainez, ms. 68 de la Biblioteca del Duque de Gor (Granada).

La atribución a Francisco de Figueroa, que ha predominado durante mucho tiempo, carece de fundamento sólido. Con la edición de las Poesias de Pedro Lainez por A. Marín Ocete (Granada, 1950) se ha empezado a dudar seriamente de esa atribución, pues la égloga se encuentra, entre otras obras auténticas de Laínez, en un manuscrito granadino (Gor, 68) de alta autenticidad, aunque no autógrafo. Basado en esto, y además en un análisis estilístico, JoaQuín de ENtrambasaguas, en su edición de las Obras de Pedro Laynez (Madrid, 1951), se inclina decididamente por este poeta. Los argumentos en favor de Laínez se pueden corroborar con otras consideraciones. Ya Crawford indicó que el modelo de "Sobre nevados riscos levantado..." es una égloga del

:9 No comprendo cómo Meyer-Lübke clasifica tragar como derivado de $\mathrm{t} r$ a h e r e $\left(R E W^{3} 88_{41}\right)$, negándose a la vez a subordinarlo a *t rahicāre (8841a). J. SArö̈HANDy, "Gloses catalanes de Munich [de hacia 1400]", $R F, 23$ (1907), 251, atribuye análogamente cat. ant. trangolir $=$ lat. sorbo (f. $27 \mathrm{v}^{\circ}$ II) a cruce de tragar y engullir; este último, a su vez, podría explicarse por el contacto de *i ngullāre (que presuponen it. ingollare, fr. engouler, prov. engolar) con el antiquísimo verbo,

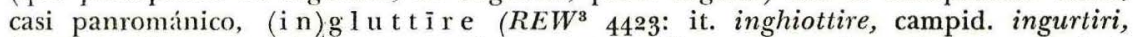
fr. engloutir, cat. englutir, etc.; agréguese lat. tardío trānsglut ti re, que refleja fr. ant. trensgloutir, registrado por GoDfFroy, y la conocida familia vulgar s u bglutt-ius, -i o, * - iāre, fuente de sollozar). Ingullāre, por su parte, postula un cruce esporádico de g u la 'garganta' con coll um 'cuello' (cf. esp. degollar < dē collā $\mathrm{re}$ ), en favor del cual abogan además tosc. ingollire (Luca) y esp. gollete, gollizo. A cat. ant. trangolir se acerca marcadamente can. trangulir, comer a trangullones 'engullir rápidamente' (L. y A. Millares). Lo que hace plausible tales cadenas de cruces, que en otras condiciones deberían inspirar desconfianza, es el carácter altamente expresivo de todo este grupo semántico. La coexistencia de g l u ttō y glūtō ya pone de manifiesto dicho expresivismo en latín. 